Archivos de Ciencias de la Educación, Vol. 12, nº 13, junio 2018, e042. ISSN 2346-8866 Universidad Nacional de La Plata.

Facultad de Humanidades y Ciencias de la Educación.

Departamento de Ciencias de la Educación.

\title{
Escuela y personas con discapacidad: integración y desintegración en tiempos de inclusión
}

\section{Cobeñas, Pilar}

Universidad Nacional de La Plata , Argentina

pilarcobenas@gmail.com

Cita sugerida: Cobeñas, P. (2018). Escuela y personas con discapacidad: integración y desintegración en tiempos de inclusión. Archivos de Ciencias de la Educación, 12 (13), e042. https://doi.org/10.24215/23468866e042

Recibido: 03 Agosto 2017 - Aceptado: 09 Mayo 2018 - Publicado: 29 de junio de 2018

(c) (1) (2) Esta obra está bajo licencia Creative Commons Atribución-NoComercial-CompartirIgual 4.0 Internacional cc) 


\title{
Escuela y personas con discapacidad: integración y desintegración en tiempos de inclusión
}

School and persons with disability: integration and desintegration in times of inclusion

Pilar Cobeñas

Universidad Nacional de La Plata, Argentina

pilarcobenas@gmail.com

\begin{abstract}
RESUMEN:
El presente artículo tiene como objetivo comunicar algunos de los resultados que arrojó una investigación destinada a conocer las visiones de sí de jóvenes mujeres con discapacidad inscriptas en diversas dinámicas de escolarización en el marco de la ratificación de la Convención sobre los Derechos de las Personas con Discapacidad. En dicho marco se señala que las trayectorias escolares de las personas con discapacidad son discontinuas y fragmentadas, y que el sistema educativo produce clasificaciones específicas que resultan discapacitantes sobre estos grupos. Se analizan los destinos escolares de las jóvenes mujeres con discapacidad y discuten los saberes pedagógicos que ponen en juego las instituciones para definir los destinos institucionales de las personas con discapacidad.
\end{abstract}

Palabras ClaVe: Personas con discapacidad, Mujeres con discapacidad, Educación inclusiva, Exclusión educativa.

\section{Abstract:}

This article aims to communicate some of the results of an investigation about the visions of the young women with disabilities enrolled in various dynamics of schooling in the framework of the ratification of the Convention on the Rights of Persons with Disabilities. This framework indicates that the educational paths of people with disabilities are discontinuous and fragmented, and that the education system produces specific categorisation that are disabling in these groups. The school destinations of young women with disabilities are analyzed and the pedagogical knowledge that the institutions put in play to define the institutional destinations of people with disabilities is analyzed.

KEYwords: People with disability, Women with disability: Inclusive education: Educational exclusion, Inclusive education, Educational exclusion.

\section{INTRODUCCIÓN}

El presente artículo tiene como objetivo comunicar algunos de los resultados que arrojó una investigación ${ }^{1}$ (Cobeñas, 2015) destinada a conocer las visiones de sí de jóvenes mujeres con discapacidad inscriptas en diversas dinámicas de escolarización.

Para el desarrollo de nuestro estudio hemos articulado enfoques provenientes de la teoría foucaultiana, la teoría de género y los estudios sociales de la discapacidad o Disability Studies. A partir de las perspectivas teóricas asumidas, orientamos nuestros esfuerzos a intentar dar cuenta del punto de vista de las jóvenes sobre los procesos de inclusión y exclusión educativa, al mismo tiempo que problematizamos nuestras visiones como investigadoras sobre dichos procesos (Cobeñas, 2018). Para ello definimos realizar un estudio cualitativo basado fundamentalmente en entrevistas semiestructuradas (principalmente a alumnas, pero también a otros actores de la comunidad escolar) y observaciones en cuatro escuelas comunes y especiales de la provincia de Buenos Aires, Argentina, durante un período de dos años. 
Nuestra investigación está enmarcada en una perspectiva de la discapacidad desde el llamado modelo social y de derechos (Palacios, 2017). Este modelo es producto de la articulación entre el movimiento social de personas con discapacidad y el área de estudios sociales de la discapacidad. Ambos surgen entre la década de 1970 y 1980 alrededor de los debates sobre las condiciones precarizadas de vida de las personas con discapacidad, generadas por el propio colectivo. En este marco se construyeron nuevas narrativas que permitieron desafiar las formas hegemónicas de pensar la discapacidad para identificarse como un colectivo oprimido socialmente, que lucha contra las barreras que los excluyen y discapacitan, incluidas las formas de educación segregadas (Barton, 2009).

Desde este nuevo paradigma se denominó a las formas hegemónicas de entender la discapacidad como modelo médico. Los efectos del paradigma del modelo médico producen un tipo de relaciones sociales mediadas por la concepción de las personas con discapacidad como inferiores biológicamente, que contribuyen a sostener una mirada eugenésica, de tragedia personal y dependencia sobre la discapacidad (Oliver, 2008).

Una de las victorias más importantes del movimiento social de personas con discapacidad en términos de derechos es la Convención sobre los Derechos de las Personas con Discapacidad (ONU, 2008, en adelante "la Convención"), firmada (2006) y ratificada (2008) por la Argentina. Según el artículo 24 de la Convención, Argentina se ha comprometido a modificar su sistema educativo en pos de una educación inclusiva (Palacios, 2008, 2017; Pérez Bello, 2015). ${ }^{2}$

Cuando la Convención se refiere al término "educación inclusiva" no se considera como un sinónimo de exclusión, segregación ni integración educativa. Inclusión implica la modificación de un sistema educativo partiendo de la base de que todos y todas los y las alumnos/as deben y tienen derecho a aprender juntos/as, independientemente de sus características (Ainscow, 2004, 2008). La Convención obliga, así, a los Estados parte a transformar sus sistemas educativos en inclusivos, partiendo de caracterizar como discriminación a los formatos escolares que sostienen la exclusión educativa o derivación de un/a alumno/a a una escuela segregada a causa de su discapacidad. Es la escuela la que debe modificarse en función de las características de su alumnado y no el alumnado el que debe adaptarse a la institución o, en caso de no conseguirlo ser derivado, excluido, segregado (Pérez Bello, 2015).

\section{OBSTÁCULOS EN EL ENCUENTRO CON MUJERES}

En el presente artículo presentaremos algunos aportes sobre las dinámicas de escolarización de las jóvenes mujeres alumnas con discapacidad. Un análisis estadístico desarrollado en nuestra tesis de Maestría (Cobeñas, 2015) muestra que aun cuando las mujeres jóvenes con discapacidad superan en número a los varones, se encuentran menos escolarizadas. La persistente desigualdad de oportunidades educativas se puso en evidencia apenas comenzamos con el trabajo de selección de las instituciones a partir del perfil de alumnas que habíamos elegido para este estudio. Las posibilidades de elección de las escuelas se vieron gradualmente reducidas a medida que avanzaban las reuniones con las inspectoras, las directoras y otras autoridades educativas, dado que cuando repasaban las planillas de matrícula escolar buscando instituciones a las que asistieran alumnas jóvenes con discapacidad, el universo se reducía notablemente. La desigualdad entre varones y mujeres en lo que se refiere a las personas con discapacidad es fácilmente apreciable en la vida cotidiana de las instituciones. Así, mientras conversábamos sobre esta cuestión con la directora de una escuela especial, ella asentía señalando que:

(...) en la escuela hay solamente dos mujeres como vos pedís (...) [hace gestos como sorprendida por la situación que describe] tenés razón en que hay diferencias entre cuántos alumnos y alumnas. En esta escuela, bah y en todas las que conozco que fui, siempre hay muchas menos alumnas que alumnos. En los pequeños no es tan así, sobre todo por los avances de la medicina, lo que ha hecho que muchos chicos y chicas que se morían antes de los 3 años, ahora no, y que eso, en las mujeres se nota más, antes eran las que más se morían, y ahora con los avances de la ciencia, el número es más o menos parecido entre chicas 
y chicos [niños y niñas] que vienen a la escuela (Entrevista a F, directora de una escuela especial para "multiimpedidos") (Cobeñas, 2015, p. 90).

Asimismo, constituyó un obstáculo el hecho de no contar con los datos actualizados acerca de la condición de integradas/no integradas de las alumnas matriculadas en escuelas especiales. Sin contar con estos datos nos encontramos con que alumnas que habían sido referidas como integradas, debían ser consideradas como no integradas, puesto que la escuela especial había dispuesto a partir de determinado momento, que no podían continuar asistiendo a la escuela común. Estos cambios en la situación escolar de las alumnas no estaban registrados en la base de datos con la que contaban las inspectoras. Asimismo, hemos indagado sobre los datos estadísticos disponibles intentando buscar en qué medida la experiencia de las alumnas que participaron de este estudio es representativa de la población total de alumnas con discapacidad y no hemos encontrado respuesta a esta cuestión en ninguna base de datos de ningún organismo oficial. Es preciso señalar que consideramos que esta situación de falta de información es grave, puesto que nos impide llegar a conclusiones que puedan ser relativamente generalizables, así como identificar situaciones, en términos de su frecuencia de aparición, que impliquen la reformulación de políticas educativas en lo que se refiere a la inclusión educativa de personas con discapacidad y mujeres, en particular a las escuelas comunes, ambos derechos previstos en los artículos 24 y 31 de la Convención sobre los Derechos de las Personas con Discapacidad, Ley 26.378.

\section{MUJERES CON DISCAPACIDAD: TRAYECTORIAS ESCOLARES MARCADAS POR LA (IN)EDUCABILIDAD E (IN)INTEGRABILIDAD}

En el marco de nuestra investigación pudimos registrar que el conjunto de mujeres jóvenes con discapacidad que formaron parte de nuestro campo de estudio atraviesan procesos de escolarización marcados por la exclusión y las rupturas en sus trayectorias. Algunas de ellas han iniciado sus estudios en escuelas especiales pasando al sistema común en calidad de integradas para luego volver al sistema especial. El pasaje de la integración a la desintegración escolar produce efectos duraderos en la subjetividad y en su condición de docilidad. El traslado de los cuerpos a través de distintas instituciones sin ninguna participación de las sujetas en esa movilidad interinstitucional expresa una concepción de esa sujeta en que el cuerpo es de otros. Es el territorio donde otros escriben su destino. Para otras mujeres que han pasado de la escuela especial a la común y luego finalizado sus estudios en escuelas de adultos o talleres protegidos significa la posibilidad de que sus cuerpos sean reconocidos como cuerpos de algún modo productivos en términos de las relaciones socioeconómicas, aunque debemos resaltar que son condiciones de trabajo precarizados o en condiciones de explotación. Por último, están aquellas para las cuales su recorrido de escuela especial a otra escuela especial, o de la escuela especial a un centro de día. Para todas estas mujeres, el tránsito por las experiencias de lo escolar está vinculado a emociones como el dolor, la frustración, la impotencia y la imposibilidad, contribuyendo de una manera innegable a imponerles visiones de sí discapacitantes consolidadas en procesos de aislamiento social. Un ejemplo del punto de vista que las jóvenes tienen acerca de sus trayectorias escolares puede observarse en la narración de una joven que obtuvo un certificado de estudios primarios en una escuela común expresando que:

(...) fue medio complicado, porque yo tuve toda mi escolaridad una maestra integradora que me apoyo toda la primaria y no, o sea, no todas las maestras eran iguales, más complicado fue cuando yo iba a quinto, cuarto, ya se me empezaba a complicar un poco más, y después, bueno, yo no vivía a acá en La Plata, yo vivía en la Costa [Atlántica de la provincia de Buenos Aires] y después hice la primaria allá en la Costa, y, bueno, ahí en un principio como en octavo ya no podía ya, y si seguía repetía de año, los directores al final decidieron darme un certificado y que termine ahí (Entrevista a I, joven mujer activista por los derechos de las personas con discapacidad) (Cobeñas, 2015, p. 91).

Asimismo, la misma joven con discapacidad, que actualmente es activista por sus derechos en una organización de jóvenes con discapacidad, explicó en relación a su escolaridad que: 
(...) el tema es que la gente como que, siempre decimos lo mismo con los chicos, desde que empezamos el grupo. Siempre decimos que, antes, yo antes pensaba que el problema era yo, pero nos dimos cuenta que en realidad no, que en realidad el problema es el resto, la sociedad que no nos mira de otra manera y que no nos acepta como somos (...) Es lo que en general siempre decimos que en las escuelas, en general, es como que siempre te rechazan, siempre te tiran para abajo, o como que... no sé cómo decírtelo, como que no te integran (Entrevista a I, joven mujer activista por los derechos de las personas con discapacidad) (Cobeñas, 2015, p. 91).

Otra alumna joven con discapacidad, quien debió continuar sus estudios en una escuela para adultos luego de repetir cuatro años seguidos en su escuela común la materia matemática, nos relató cómo se refirió a ella una profesora de esa misma materia en su escuela actual:

(...) H: me echó de la clase y me dijo que a ella no le pagaban doble por enseñar a retrasados.

E: ¿y vos le respondiste?

H: no. Pero me dio mucha bronca. Pero la profesora es de matemática y yo no entiendo matemática, pero después esa profesora sacó carpeta y ahora tenemos otra profesora de matemática que es buena porque explica y ahora tengo 10 . Tengo miedo de qué va a pasar cuando se le termine la carpeta a la otra profesora (Entrevista a $\mathrm{H}$, una joven alumna con discapacidad integrada en escuela de adultos) (Cobeñas, 2015, p. 92).

Así, hemos identificado en estas dos jóvenes, como en otras, que aún dentro de situaciones que el sistema educativo denominaría como de integración, o peor aún, caracterizadas como de inclusión, las jóvenes alumnas con discapacidad sufren la exclusión, ya sea en materias específicas, o directamente de la escuela común con el argumento de su discapacidad. Estas prácticas son violatorias de derechos expresamente establecidos en la Convención sobre los Derechos de las Personas con Discapacidad (Cobeñas, 2015, 2016).

\section{VIOLENCIAS Y DERECHOS}

El conjunto de jóvenes entrevistadas pudo referirnos diversas situaciones de violencias y violación de derechos. Un ejemplo de ello lo da una alumna con discapacidad (de quien hemos recuperado la previa cita sobre la materia "matemática") que asiste actualmente a una escuela de adultos, debido a que, tras haber repetido diversos años en una escuela secundaria común, fue derivada a una escuela de adultos bajo el criterio de “sobreedad". Dicha joven alude a una situación vivida junto al profesor de la materia Historia en su escuela actual y que describió como angustiante:

(...) yo tengo la carpeta completa de historia y era la única que la tenia completa y me merecía un 8 , pero mis compañeros me contaron que el profesor dijo que me ponía 7 porque yo era discapacitada. Entonces le hice una carta a la directora contándole esto y diciéndole que era injusto y me discriminaba que me pongan un 7 por discapacitada porque yo tengo la carpeta completa y merezco un 8 (Entrevista a $\mathrm{H}$, una joven alumna con discapacidad integrada en escuela de adultos) (Cobeñas, 2015, p. 92).

Si bien en este caso la alumna logró poner en práctica una estrategia de resistencia a la injusticia que significaba que las calificaciones estuvieran condicionadas al hecho de ser una persona con discapacidad y a demandar su derecho a estar en el aula en igual derecho y condición que el resto de sus compañeros/as, al ser consultada nos refirió que no tenía conocimiento de la existencia de grupos organizados de personas con discapacidad ni de las leyes que protegen sus derechos. Lo que es observable en las indagaciones realizadas en las instituciones educativas es que no hay ninguna formación en derechos específicos, no sólo sobre los derechos de las personas con discapacidad sino de los derechos para el conjunto de los alumnos que asisten a la escuela.

Consultamos a directores, directoras y maestras integradoras acerca de las situaciones de injusticia percibidas por las alumnas en su relación con profesores y profesoras. Todos/as coincidieron en que siempre hay docentes "más resistentes" a la incorporación de alumnos con discapacidad en las escuelas comunes y que, inclusive, han llegado a negarse a enseñar a personas con discapacidad o a solicitar su exclusión del aula. Esto expresa las diferentes formas en que se viola el derecho a la educación inclusiva, y a la educación en general, 
ya que se llega al punto de negar la presencia en el aula de las personas con discapacidad, lo que es atentatorio contra la integridad personal de la alumna con discapacidad. No deja de sorprender la forma recurrente en que se violan los derechos de las mujeres con discapacidad en su experiencia escolar cotidiana y la ausencia de cualquier tipo de protección de esos derechos por parte de las autoridades escolares, y de los docentes en general. En este sentido, consideramos que es necesario destacar que no alcanza con permitir que las jóvenes mujeres con discapacidad asistan a la escuela común para denominar a esa práctica como educación inclusiva o integración. Las escuelas y sus agentes deben transformarse para poder alojar a esas alumnas en sus aulas garantizando plenamente sus derechos y, de ese modo, evitar que atraviesen por situaciones de violencia cultural, simbólica y hasta física.

En la narrativa de la alumna que exponía su experiencia escolar con los profesores de historia y matemática, pudimos observar el desarrollo de diferentes estrategias de respuesta a esas situaciones. En el caso del aula de matemática, la alumna dice "yo no entiendo matemática" y es capaz de soportar, entre el enojo y la angustia, la agresión verbal de la docente. La experiencia escolar le ha enseñado que "ella no es buena en matemática", es decir, que tiene que aceptar su precaria relación con el saber escolar, condición que se renueva cuando, en el aula de historia, el profesor baja la calificación de su trabajo con el argumento de su discapacidad. La discapacidad es aquí interpretada como una barrera al aprendizaje. Sin embargo, en esta oportunidad, la alumna sabe que ha cumplido con lo esperado por el docente, y es capaz de desarrollar una estrategia de resistencia, teniendo una actitud proactiva en defensa de sus derechos (advocacy), escribiendo una nota a la directora, usando los canales institucionales. La relación docente-alumna en las narraciones señaladas se restringe a una forma de comprender los procesos de transmisión del conocimiento escolar pero no involucra comprender una relación con el saber. De este modo observamos cómo la relación docente-alumna puede afectar las visiones de sí de las jóvenes alumnas con discapacidad, y también cómo dentro de esa relación ellas pueden producir estrategias de resistencia (Foucault, 1988) frente a prácticas que involucran agresión, desprecio, intimidación, que resultan discapacitantes y subalternizantes. En suma, que violan el conjunto de sus derechos.

\section{CONSTRUYENDO VISIONES DE Sí DEVALUADAS}

Hemos sumado en las entrevistas a diferentes actores del sistema educativo. En el caso de la alumna a la que venimos haciendo referencia, entrevistamos a la asistente terapéutica, que es quien la acompaña en las clases. En una parte de su relato resalta que:

Ella [la alumna] en la escuela anterior nunca se habló con nadie ni tenía amigas. Le cuesta mucho hablar y tienen miedo de equivocarse al hablar. Tienen miedo al prejuicio, le tiene miedo a los profes al preguntar y no entendía y se iba con eso a la casa, por eso le iba a mal. Desde que le puede preguntar a los profes le va mejor en la escuela (Entrevista a E, Acompañante Terapéutica de H, una joven alumna con discapacidad integrada en escuela de adultos) (Cobeñas, 2015, p. 94).

Además, comenta que "desde que le va mejor en la escuela se empezó a maquillar y a vestir mejor". Siguiendo la interpretación de la asistente terapéutica, esta alumna con discapacidad no evidencia ningún impedimento para concurrir a la escuela común, tal como fuera señalado en el diagnóstico que acordaron la escuela común con la especial. De tal modo, las experiencias que fue atravesando en la escuela común delinearon visiones de sí discapacitantes que se expresaban en su miedo a preguntar y a participar por su temor a equivocarse. Estrategias de defensa frente a docentes con prácticas violentas y estigmatizantes. En este sentido, la escuela produce barreras al aprendizaje de las jóvenes mujeres con discapacidad, dado que no son las condiciones ni sus capacidades el objeto del juicio escolar ${ }^{3}$ sino los efectos simbólicos que la discapacidad entendida como estigma ${ }^{4}$ establece como marca indeleble en el cuerpo de las alumnas.

Otro caso surgido en nuestro trabajo de campo, nos encontramos con una joven mujer con discapacidad que actualmente es activista por los derechos de las personas con discapacidad, pero cuya historia escolar 
muestra el tránsito por diferentes escuelas especiales, de las que fue sistemáticamente excluida bajo el argumento de una condición de "ineducabilidad", siendo clasificada como multiimpedida. Habiendo accedido recientemente al sistema de comunicación alternativo aumentativo, ante nuestra pregunta acerca de su historia escolar, nos respondió que, sólo recordar su escolarización le produce un dolor de tal magnitud que siente que todavía no está lista para hablar de esa experiencia. Precisamente esto da cuenta de la relevancia que tiene ampliar las investigaciones acerca de los procesos de escolarización de las jóvenes mujeres con discapacidad. En este sentido, es necesario dar visibilidad a aquellos relatos que han sido silenciados por las propias mujeres por el dolor que les han generado. El alto silenciamiento que producen las prácticas de los otros también son obstáculos para luchar contra las formas de exclusión escolar. Consideramos que la investigación debe recuperar las voces y campos de experiencias de las mujeres con discapacidad, en función de pensar políticas, prácticas y estrategias en torno a la inclusión.

\section{TraYectorias ESCOLARES DIFERENCIADAS}

En el conjunto de mujeres que formó parte de este estudio se puede observar que lo común a todas ellas es que tienen trayectorias escolares discontinuas y fragmentadas. La posición de alumno/a para las personas con discapacidad es una posición inestable, es decir, en tanto el discurso pedagógico no impulse las ideas de estabilidad en la permanencia en las instituciones, de mantenimiento del grupo de pares, de relaciones más duraderas en el tiempo docente-alumno que hace que un profesor pase junto con su grupo al año siguiente, así como en la continuidad de otras figuras adultas dentro de la institución, las personas con discapacidad se ven sometidas a formas de diagnóstico y evaluación permanente afectando su permanencia en la vida institucional y en la continuidad de las relaciones con otros (amigos/as, compañeros/as, profesores/as). Por otra parte, el alumnado clasificado como con discapacidad está sujeto a las decisiones de un equipo que varía en su composición a lo largo de los años, lo que implica también una variación de los criterios que se ponen en juego sobre ese mismo sujeto.

En este contexto, se comprende que los/as alumnos/as con discapacidad cambien varias veces de grupo de compañeros dentro de una escuela (porque repiten el grado o se define la "permanencia" en un año) o por que asisten a diferentes instituciones a lo largo de su escolaridad, lo que parece una tendencia dentro de la población estudiada. Hemos registrado que, en el marco de los procesos observados, tanto las familias, como los niños, niñas y jóvenes con discapacidad expresan de forma insistente su deseo de permanecer en un mismo curso o institución de educación común. Sin embargo, son extrañas las ocasiones en que dichas opiniones son tenidas en cuenta por el equipo de gestión y los/as docentes de las escuelas comunes o especiales. Ellos generalmente se atribuyen la legitimidad en términos de autoridad y saber para decidir qué es lo mejor para los/as niños/as/ y jóvenes con discapacidad, lo que con frecuencia resulta en una vuelta a la escuela especial. O como lo expresa una directora de escuela especial:

(...) cuando los chicos son grandes y terminan $6^{\circ}$ se reúne a la escuela con la familia, y el alumno para definir si va a la escuela secundaria o al CFI [Centro de Formación Integral]. Los chicos nunca quieren ir al CFI, pero es lo mejor para ellos (Entrevista a D, directora de una escuela especial para personas con discapacidad intelectual) (Cobeñas, 2015, p. 97).

En el mismo sentido, una maestra integradora nos explicó que:

(...) los padres son muy sobreprotectores, siempre están de acuerdo con ir a común, en general se resisten a especial (Entrevista a C, docente de una escuela especial para personas con discapacidad intelectual) (Cobeñas, 2015, p. 97).

Este tipo de comentarios aparece comúnmente en las entrevistas realizadas al personal de las escuelas especiales. En esos encuentros observamos una fuerte resistencia a la presencia de personas con discapacidad en escuelas comunes y un consecuente despliegue de estrategias para "devolver" a la escuela especial a aquellos y aquellas alumnos/as con discapacidad que han logrado la integración. 
Hemos notado también que docentes y directivos de instituciones educativas especiales perciben como una intromisión y hasta, en ocasiones, como un ataque, los reclamos de las familias para integrar a sus hijos e hijas con discapacidad en escuelas comunes. En este sentido, una directora de escuela especial para personas con discapacidad intelectual nos informó que un $20 \%$ de su matrícula se encontraba integrada en escuelas comunes y describió a "su alumnado" de la siguiente manera:

La matrícula de la escuela se divide según la patología. En general el $80 \%$ de la matrícula son repitentes, por ejemplo, tienen 12 años y están en $2^{\circ}$ grado. Tienen un déficit por la situación social, por lo que deviene de la situación social y económica y sus carencias. El otro 20\% tiene algún diagnóstico genético, alguna discapacidad, atención temprana. (Entrevista a D, directora de una escuela especial para personas con discapacidad intelectual) (Cobeñas, 2015, p. 97).

Aquí la directora ha definido explícitamente a sus alumnos y alumnas con discapacidad intelectual como asociados a "patologías": dentro de esta categoría entra un arco que va desde lo que ella entiende como características genéticas (cuestiones del orden de la naturaleza, la biología o el instinto) a la pobreza (las condiciones materiales y simbólicas de vida de los sectores populares). Este juicio expresa la forma en que se comprende la relación entre lo patológico y lo normal para el establecimiento en estado práctico de un poder de normalización.

Esta oposición de lo normal y lo patológico organiza las bases del modelo médico de la discapacidad que, como vimos, supone que las personas poseen alguna patología, déficit o anormalidad y que deben ser segregadas en alguna institución a fin de restituir la normalidad. Este modelo no considera a las personas con discapacidad como sujetos de derecho y les define destinos escolares y sociales asociados al aislamiento, la dependencia y la inutilidad, privándolos de todo ejercicio de ciudadanía, entre otras consecuencias (Cobeñas, 2015, 2016; Ainscow, 2004, 2008; Barton, 1998). Asimismo, la misma directora agregó que:

(...) cuando los padres piden que se los integre se les pide que busquen una escuela común. Está instalado que es genético y que la sociedad debe aceptarlos, pero es peor, y a medida que crecen es peor [para los y las alumnos/as con discapacidad] estar en la escuela común. Se generan, entre otros, problemas de autoestima que vienen con la adaptación al maestro integrador. Así, cuando se ve que una secundaria no va a ayudar se decide que continúe en sede [escuela especial] para hacer formación laboral. (Entrevista a D, directora de una escuela especial para personas con discapacidad intelectual) (Cobeñas, 2015, p. 98)

Una maestra integradora de esa escuela expresó que:

(...) uno se pregunta cómo va a pasar este chico a primaria (...) Hoy por hoy integración está difícil porque los padres deciden y tu trabajo no sirve, sin tener en cuenta las capacidades y su hijo. Por ejemplo, el de una nena muy sumisa, no tenía los mismos intereses que el grupo. ¿Qué hacemos, que termine el último año de la primaria común? No se tomaba el micro. Finalmente decidimos que venga acá [la derivaron de la escuela común a la escuela especial]. El primer día no estaba a gusto. A los tres días era otra nena. Acá son 10 alumnos y socializó bien. (Entrevista a C, docente de una escuela especial para personas con discapacidad intelectual)(Cobeñas, 2015, pg. 98)

En estos fragmentos podemos identificar varias cuestiones. Por un lado, las formas de ver a sus alumnas por parte del personal docente y de gestión de las escuelas especiales que condiciona las posibilidades de integración, así como las de su participación ciudadana, y, claro, de efectivización de sus derechos en general. Por otra parte, se observa la relación problemática entre familia y escuela en relación a la educación de las personas con discapacidad. La integración aparece como una demanda de los padres, en tanto que los agentes escolares en nombre de la institución descreen de las políticas de inclusión o integración. Por el contrario, sostienen y justifican la segregación escolar de las personas con discapacidad en instituciones especiales. Parte de esos argumentos están referidos a los problemas de autoestima que potencialmente presentarían las alumnas que asisten a una escuela común. Desde nuestra perspectiva, esos "problemas de autoestima" que se mencionan, no son sino efectos generados por el tratamiento pedagógico y social que el personal docente de la institución de escuela especial tiene hacia las alumnas, personal que puede, por ejemplo, justificar la exclusión escolar de una alumna por una caracterización tan difusa como la de llamarla "sumisa" o resaltar que "no tenía 
los mismos intereses que el grupo". Dichas sentencias resultan suficientes para establecer juicios que legitiman el pasaje de una alumna de una escuela común a una escuela especial, aun en contra de sus deseos explícitos.

\section{Procesos DE INTEGRACIÓN: EXCLUSIÓN EN LA INCLUSIÓN}

En este punto se hace necesario describir aquellas condiciones que fueron definidas para la integración de la mayoría de las alumnas entrevistadas. Si en una escuela común se inscribe una persona con discapacidad, dicha escuela se vincula a una escuela especial para acordar un proyecto de integración. Dicho proyecto es producido por el equipo interdisciplinario de la modalidad especial con base en el legajo y documentos provistos por la institución escolar común, así como en función de conversaciones formales e informales con docentes y equipo directivo y de orientación educativa de esa institución. De este modo, un proyecto pedagógico puede ser producido sin ni siquiera haber visto ni interactuado con el alumnado. Entre los casos considerados, hemos registrado que en muy pocas oportunidades se ha realizado una o una serie reducida de entrevistas. $\mathrm{Si}$ el proyecto de integración es aprobado por las autoridades educativas se designa a una docente integradora de la escuela especial que acompaña durante dos horas reloj por semana a la alumna dentro del aula. Esa docente es la que evaluará y más tarde decidirá si esa niña o joven continúa en la escuela común o debe ser recomendada para escuela especial.

Las personas con discapacidad, sus familias y representantes de las diferentes organizaciones que las nuclean, principalmente en la región bonaerense, han manifestado que resulta muy frecuente que las escuelas especiales les recomienden que su hijo/a no vaya a una escuela común con el argumento central que "es lo mejor para el niño o la niña". Es habitual observar la forma en que los agentes escolares exhortan a los familiares para lograr que la alumna o el alumno con discapacidad que está integrado en una escuela común retorne a la escuela especial. En todos los casos analizados, el equipo directivo o el personal docente de las escuelas especiales justificaban sus decisiones en base al conocimiento de sus agentes (docentes especiales, terapistas ocupacionales, psicopedagogos, fonoaudiólogos, psicólogos, psiquiatras, médicos) (Cobeñas, 2014).

El conjunto de procedimientos descriptos incumple lo establecido en la Convención sobre los Derechos de las Personas con Discapacidad dado que es contradictorio con el principio de inclusividad que debería orientar el derecho de los y las alumnos/as con discapacidad a recibir educación en la escuela común. Los proyectos de integración en el sistema educativo bonaerense tienen como punto de partida al alumno o alumna como individuo, lo que presupone que es ese el locus privilegiado hacia dónde dirigir la mirada y en que se establecen las posibilidades de su educación. De este modo, las limitaciones o incapacidades se asientan en el cuerpo del alumno y no en el saber y en la práctica pedagógica. Esta lógica responde a lo que se denomina modelo médico de la discapacidad por oposición al modelo social y de derechos humanos. En segundo lugar, el proyecto de integración se elabora en base a un legajo en el que predominan los datos y diagnósticos médicos del alumno o de la alumna. Además, se consideran los informes de la docente integradora quien, como fue señalado, concurre un mínimo de tiempo a la escuela común, a razón de dos horas por semana, por lo que es impensable evaluar siquiera el impacto de su presencia en la formación de la alumna, y mucho menos que conozca acabadamente su desempeño escolar en cualquiera de sus aspectos. Esta docente es la que luego evaluará el (mal) desempeño de esta alumna y definirá si debe volver a la escuela especial dada a su imposibilidad de permanecer en la escuela común. El proceso descripto que involucra una compleja trama de procedimientos e intervenciones en que las voces de las alumnas permanecen silenciadas, fabrica trayectorias educativas fracturadas, marcadas por lo que el campo escolar define como el fracaso escolar y traccionadas hacia la escuela especial de las mujeres y personas con discapacidad en general. 


\section{CONSIDERACIONES FINALES}

Nuestro sistema educativo tiene aún muchas deudas en torno a la educación inclusiva. En este trabajo hemos dado cuenta de cómo las escuelas clasifican y dividen a las mujeres con discapacidad en categorías como integradas/integrables/inintegrables, en base a discursos médicos y pedagógicos definiendo así los destinos institucionales que les serán asignados y produciendo trayectorias escolares intercambiables, discontinuas y fragmentadas.

Si bien la exclusión, segregación e integración escolar son consideradas formas discriminatorias de educación en el marco de los acuerdos internacionales de derechos humanos, continúan teniendo vigencia en nuestro país. Dichos modelos parten de la idea que el alumno o alumna con discapacidad posee un déficit y debe adaptarse a la escuela común, o fracasar, -fracaso que estará justificado por la imposibilidad de aprendizaje del alumno/a a causa de su impedimento, déficit, in/dis-capacidad-mirada que no lo/a reconoce como sujeto/a de derecho. Este paradigma y sus prácticas son violatorias de los derechos consagrados en la Convención sobre los Derechos de las Personas con Discapacidad, particularmente en su artículo 24 sobre Educación Inclusiva, como ya lo hemos establecido.

De modo que consideramos imprescindible continuar estudiando para profundizar la comprensión de los procesos de escolarización de los grupos más vulnerables, como el de mujeres con discapacidad, contribuyendo a visibilizar las demandas de los colectivos sobre las múltiples formas de exclusión educativa que implican, en definitiva, diversas formas de exclusión social.

\section{Bibliografía}

Ainscow, M. (2004). El desarrollo de sistemas educativos inclusivos: ¿Cuáles son las palancas de cambio?. Journal of Educational Change, 5 (4), 1-20.

Ainscow, M. (2008). Por una educación para todos que sea inclusiva: ¿Hacia dónde vamos ahora?. Perspectivas, 38 (1), $17-45$.

Barton, L. (Comp.) (1998). Discapacidad y sociedad. Madrid: Morata.

Barton, L. (2009). "Estudios sobre discapacidad y la búsqueda de la inclusividad. Observaciones. Studies on disability and the quest for inclusivity: Some observations", en Revista de educación, 349, 137-152.

Bourdieu, P. y Saint Martín, M. (1998). Las categorías del juicio profesoral. Propuesta Educativa, 9(19), 4-17.

Cobeñas, P. (2014). Buenas prácticas inclusivas en la educación de personas con discapacidad en la provincia de Buenos Aires y desafios pendientes. Buenos Aires: Asociación por los Derechos Civiles.

Cobeñas, P. (2015). Visiones de si de jóvenes mujeres con discapacidad que asisten a escuelas públicas de la provincia de Buenos Aires. (Tesis de Maestría. Universidad Nacional de La Plata). Recuperada de http://www.memoria.fah ce.unlp.edu.ar $/$ library? $=\mathrm{d} \& \mathrm{c}=$ tesis\&d $=\mathrm{Jte} 1206$

Cobeñas, P. (2016). Jóvenes mujeres con discapacidad en escuelas públicas de la provincia de Buenos Aires: problematizando los procesos de inclusión y exclusión educativa (Tesis de Doctorado. Universidad Nacional de La Plata). Recuperada de: http://www.memoria.fahce.unlp.edu.ar/library?a=d\&c=tesis\&d=Jte1213

Cobeñas, P. (2018).Investigar con mujeres con discapacidad: reflexiones epistemológicas y metodológicas desde el enfoque feminista-emancipador. Revista Brasileira de Estudos Pedagógicos, 99(251),132-147.

Cobeñas, P., Fernández, C., Galeazzi, M., Noziglia, J., Santucciones, G., Schnek, A. (2017). Educación inclusiva y de calidad, un derecho de todos. CABA: COPIDIS-Grupo Art. 24.

Foucault, M. (1988). El sujeto y el poder. Revista mexicana de sociología, 3-20.

Goffman, E. (2008). Estigma: la identidad deteriorada. Buenos Aires: Ed. Amorrortu.

Oliver, M. (2008). "Políticas sociales y discapacidad. Algunas consideraciones teóricas”. En: Barton, L. (Comp.) Superar las barreras de la discapacidad: 18 años de "Disability and society". Madrid: Ed. Morata. 
Palacios, A. (2008). El modelo social de discapacidad: orígenes, caracterización y plasmación en la Convención Internacional sobre los Derechos de las Personas con Discapacidad. CERMI.

Palacios, A. (2017). “El modelo social de discapacidad y su concepción como cuestión de derechos humanos", en Revista Colombiana de Ciencias Sociales, 8(1), 14-23.

Pérez Bello, J. I. (2015). El derecho a la educación inclusiva. Análisis de la jurisprudencia del Comité sobre los derechos de las personas con discapacidad de Naciones Unidas, Revista Derecho Privado. Año III, Nº 10, p. 227. CABA: Ministerio de Justicia y Derechos Humanos de la Nación, Adajus-Infojus.

Ley de Educación Nacional N²6.206, 2006.

Ley de Educación Provincial N 13.688, provincia de Buenos Aires, 2006.

Organización de las Naciones Unidas. Convención por los Derechos de las Personas con Discapacidad y su Protocolo Facultativo aprobados el 13 de diciembre de 2006.

\section{Notas}

1 En el marco de la Tesis de doctorado titulada "Jóvenes mujeres con discapacidad en escuelas públicas de la provincia de Buenos Aires: problematizando los procesos de inclusión y exclusión educativa”. Doctorado en Cs. de la Educación, UNLP. Directora: Dra. Ma. E. Martínez, Co-directora: Dra. Ma. L. Femenías. 2016 y de la Tesis de Maestría titulada "Visiones de sí de Jóvenes mujeres con discapacidad que asisten a escuelas públicas de la provincia de Buenos Aires". Maestría en Educación, UNLP. Directora: Dra. Ma. E. Martínez. 2015.

2 Ver, por ejemplo, el Informe alternativo al informe presentado por el Estado Argentino, ante el Comité de la OEA que monitorea el cumplimiento de la Convención Interamericana para la Eliminación de Todas las Formas de Discriminación contra las Personas con Discapacidad, CIADDIS, por el Grupo Art. 24 por la Educación Inclusiva, 2016; el Informe alternativo al informe presentado por el Estado Argentino, sobre la Convención sobre los derechos de las personas con discapacidad, por el Grupo Art. 24 por la Educación Inclusiva, 2017 y el Informe Alternativo de Argentina sobre la Convención de los Derechos del Niño, por el Colectivo de Derechos de Infancia y Adolescencia de la República Argentina, 2017.

3 "Es importante mencionar que la Convención sobre los Derechos de las Personas con Discapacidad, cuyo artículo 24 impone a los Estados que la firmaron instituir sistemas de educación inclusivos, tiene jerarquía constitucional otorgada por ley 27.044 (2014), lo cual significa que es superior a toda normativa interna, sea que se trate de leyes, resoluciones o disposiciones de carácter nacional o local". (Cobeñas et al., 2017).

4 Según Bourdieu, las taxonomías, las formas en que el cuerpo docente clasifica al alumnado, son "transmitidas en y mediante la práctica fuera de toda intención propiamente pedagógica. Estas formas de pensamiento, de expresión y de apreciación, deben su lógica específica al hecho de que, al ser producidas y reproducidas por el sistema escolar, representan el producto de la transformación que la lógica específica que el campo [escolar] impone a las formas que organizan el pensamiento y la expresión de la clase dominante" (1998, p. 19).

5 Los efectos de la estigmatización suponen unas ciertas actitudes de discriminación de los "normales" hacia la persona desacreditada, basados en el supuesto de que "la persona que posee un estigma no es totalmente humana" (Goffman, 2008, p.17). 